\section{Commentary: Getting circulations crossed!}

\author{
John D. Cleveland, MD, and \\ S. Ram Kumar, MD, PhD, FACS
}

Congenital heart disease in conjoined twins comes in 2 flavors: malformations related to shared cardiac mass due to thoracic fusion and isolated cardiac lesions in children with unrelated fusion. Twins with shared thoraces (ie, thoracopagus) have complex cardiac anomalies, often with fused ventricles. Although some twins may share minimal amounts of cardiac mass and can potentially achieve successful separation, literature detailing the separation of twins with fused ventricular mass reports very high fatality rates. ${ }^{1}$ Fusion of the heart beyond a tubular atrial or fibrous ventricular connection is considered inseparable. ${ }^{2}$ As a result, cardiac surgeons are rarely called on to care for such patients given the poor prognosis and often inseparable nature of these lesions.

About $6 \%$ of conjoined twins have congenital heart defects unrelated to their site of union. ${ }^{3}$ Albeit rare, congenital cardiac surgeons would be called on to intervene in such situations. Answers to questions about appropriate approach are influenced by the rarity of this situation. How and when should the lesions be repaired? Is separation safe in the setting of unrepaired heart defect in 1 twin? If heart repair is to be undertaken first, what is the best method of circulatory support for safe cardiac surgery? What degree of cross-circulation is to be expected during the repair? These questions become particularly relevant for omphalopagus and pyopagus twins, in whom separation affords reasonable prognoses. ${ }^{4}$

\footnotetext{
From the Division of Cardiac Surgery, Department of Surgery, Keck School of Medicine of the University of Southern California, Los Angeles, Calif, and Heart Institute, Children's Hospital Los Angeles, Los Angeles, Calif.

Disclosures: The authors reported no conflicts of interest.

The Journal policy requires editors and reviewers to disclose conflicts of interest and to decline handling or reviewing manuscripts for which they may have a conflict of interest. The editors and reviewers of this article have no conflicts of interest.

Received for publication April 27, 2020; revisions received April 27, 2020; accepted for publication April 30, 2020; available ahead of print May 6, 2020.

Address for reprints: S. Ram Kumar, MD, PhD, FACS, Heart Institute, Children's Hospital Los Angeles, 4650 Sunset Blvd, Mailstop \#66, Los Angeles, CA 90027 (E-mail: rsubramanyan@ surgery.usc.edu).

JTCVS Techniques 2020;3:305-6

2666-2507

Copyright (C) 2020 The Authors. Published by Elsevier Inc. on behalf of The American Association for Thoracic Surgery. This is an open access article under the CC BY-NCND license (http://creativecommons.org/licenses/by-nc-nd/4.0/).

https://doi.org/10.1016/j.xjtc.2020.04.023
}

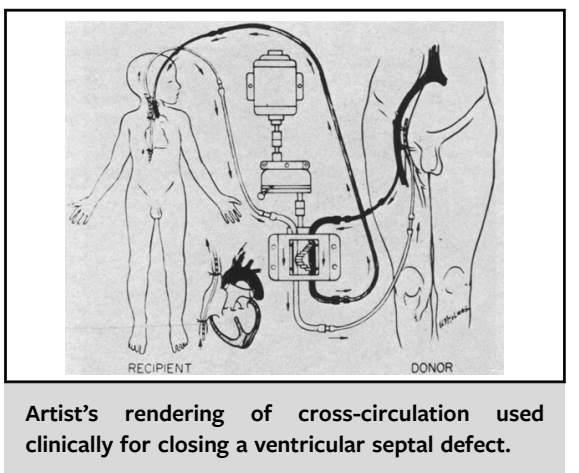

CENTRAL MESSAGE

Successful management of cross-circulation during neonatal cardiac surgery in a pyopagus twin provides a roadmap to illuminate a less frequently traveled path.

Geoffrion and colleagues ${ }^{5}$ describe a thoughtful approach to neonatal repair of hypoplastic aortic arch and ventricular septal defect in a pyopagus twin. As elegantly described by the authors, the cross-circulation between the twins posed unique challenges. The concept of crosscirculation is not novel to the field of cardiac surgery, particularly to repair of congenital cardiac lesions. In March 1954, Lillehei and colleagues ${ }^{6}$ performed the first repair of a ventricular septal defect using cross-circulation. The child's father, who shared the child's $\mathrm{O}+$ blood type, served as the biological oxygenator. The child and the father were cannulated and their circulations were connected by an extracorporeal circuit, establishing the world's first clinical cross-circulation procedure (Figure 1). ${ }^{6}$ This seminal feat was a true milestone in cardiac surgery. ${ }^{7}$ Cardiac surgery has come a long way since this pioneering effort. In contrast to Lillehei and colleagues ${ }^{6}$ intentional cross-circulation efforts, Geoffrion and colleagues ${ }^{5}$ were forced to address cross-circulation in an era where effective cardiopulmonary bypass is a routine clinical entity. The extent of crosscirculation was unpredictable. The twin with a normal heart experienced apnea when a paralytic agent was administered to the other twin, but no rhythm disturbance was observed when cardioplegia was administered. The authors, appropriately, placed both children on extracorporeal support to ensure adequate perfusion in both twins. In addition, they 


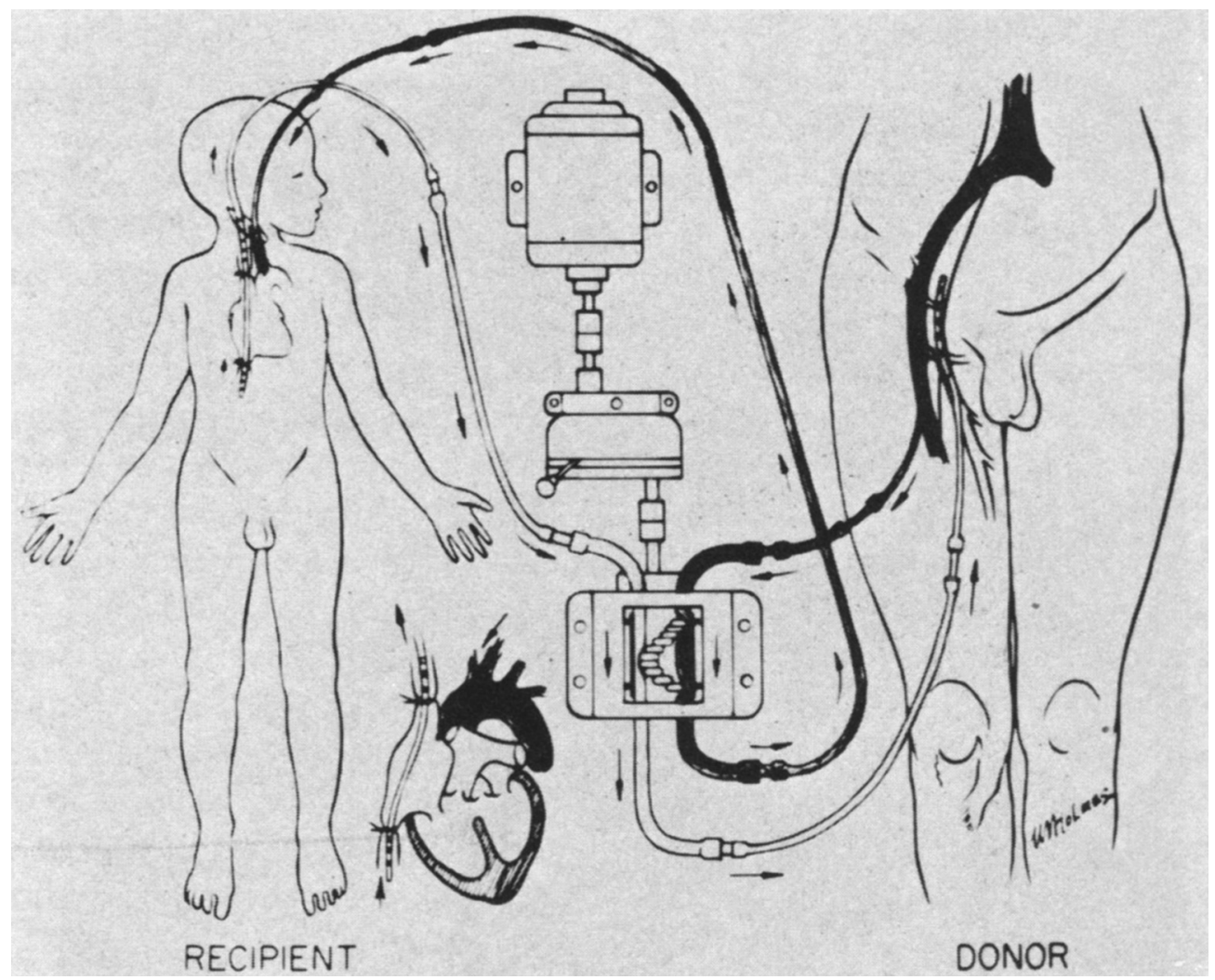

FIGURE 1. Artist's rendering of cross-circulation used clinically for closing a ventricular septal defect in a child. Arterial circuit (dark line) and venous circuit (light line) are shown. Reproduced from Warden. ${ }^{6}$

established moderate hypothermia in the twin with the normal heart to protect the twin undergoing cardiac repair from being rewarmed and experiencing cellular damage during circulatory arrest. The outcome was a resounding success.

Physician training largely focuses on pattern recognition. Repetitive exposure to usual pathologies and their therapies is expected to aid clinicians make quick diagnoses and default to standard pathways of care. Some problems in medicine beat this rule simply by their extreme rarity. Conjoined twins with congenital heart disease unrelated to their fusion is such a problem. In these circumstances, we rely on the wisdom and experience of others who may have been in these circumstances before. Geoffrion and colleagues ${ }^{5}$ are to be congratulated not only for their able management of the clinical problem, but also for choosing to use their experience to educate the rest of the community. We all now have a small roadmap that we may call upon to illuminate a less frequently traveled path.

\section{References}

1. Liu HC, Lo CW, Weng ZC, Hwang B, Lee PC. Various modalities for evaluation of a fused heart in conjoined twins. Pediatr Cardiol. 2012;33:192-200.

2. Fallon SC, Olutoye OO. The surgical principles of conjoined twin separation. Semin Perinatol. 2018;42:386-92.

3. Mutchinick OM, Luna-Munoz L, Amar E, Bakker MK, Clementi M, Cocchi G, et al. Conjoined twins: a worldwide collaborative epidemiological study of the international clearinghouse for birth defects surveillance and research. Am J Med Genet C Semin Med Genet. 2011;157:274-87.

4. Mian A, Gabra NI, Sharma T, Topale N, Gielecki J, Tubbs RS, et al. Conjoined twins: from conception to separation, a review. Clin Anat. 2017;30:385-96.

5. Geoffrion TR, Ravishankar C, Dorfman AT, Montenegro LM, Nicolson SC, Mascia CE. Repair of arch hypoplasia and ventricular septal defect in unseparated, pyopagus conjoined twins. J Thorac Cardiovasc Surg Tech. 2020;3:300-2.

6. Warden HE. C. Walton Lillehei: pioneer cardiac surgeon. J Thorac Cardiovasc Surg. 1989;98:833-45.

7. Gott VL, Shumway NE. Cross-circulation: a milestone in cardiac surgery. J Thorac Cardiovasc Surg. 2004;127:617. 